\title{
Atrial Fibrillation in Pregnancy. A Safe Approach and Literature Review
}

\author{
Muhammad Imran Butt ${ }^{1 *}$ and Mudassar Latif ${ }^{2}$ \\ ${ }^{1}$ Department of Medicine, Sir Charles Gairdner Hospital, Australia \\ ${ }^{2}$ Medical Registrar, Sir Charles Gairdner Hospital, Australia
}

Submission: March 24, 2018; Published: May 01, 2018

*Corresponding author: Muhammad Imran Butt, Department of Medicine, Sir Charles Gairdner Hospital, Hospital Avenue, Nedlands, Perth, WA 6009, Australia, Email: drimran193@gmail.com

\begin{abstract}
Pregnancy is associated with a range of haemodynamic and physiological changes including volume expansion, increase in cardiac output, a fall in systemic vascular resistance, increase in heart size and rise in heart rate [1]. These physiological changes can induce new onset of cardiac arrhythmias in a patient with or without structural heart disease. However, the prevalence of Atrial fibrillation is rare in pregnancy and if present there is likely to be an underlying structural heart disease or metabolic disturbances. The literature on exact data, prognosis and management is limited. It is important for a physician to know how to manage stable and unstable arrhythmias in pregnancy without compromising the outcome of pregnancy. Symptomatic women who fail to respond to medical therapy may need DC cardioversion.
\end{abstract}

\section{Case Report}

A 32-year-old lady G1 P0 presented for routine antenatal visit during 32 weeks of gestation. She suddenly developed severe palpitations with chest discomfort. Her pregnancy had been uncomplicated so far with normal blood tests one week prior to the visit. She did not report any infective symptoms and had remained well throughout her pregnancy. She did not have any significant medical and family history. She never smoked cigarettes and drank alcohol occasionally but had not drank alcohol in pregnancy. She never used any abusive drugs. ECG showed atrial fibrillation with rapid ventricular response of 150 per minute (Figure 1). Her blood pressure was $110 / 55 \mathrm{~mm}$ of $\mathrm{Hg}$ and temperature was normal. Her jugular venous pulse was not raised and on auscultation of her heart there was no murmur and there were no abnormal sounds on auscultation of her chest. She was given doses of intravenous metoprolol with a total dose of $10 \mathrm{mg}$ with partial response. Her electrolytes, full blood count, D- dimer and chest X-ray were normal. Fetal heart rate and cardiotocography (CTG) were within normal limits. She was admitted in coronary care unit. Her blood pressure dropped down to $85 / 50 \mathrm{~mm}$ of $\mathrm{Hg}$ with heart rate between 100 to 110 per minute and remained in atrial fibrillation. After discussion about risks and benefits of cardioversion she underwent DC cardioversion and reverted to sinus rhythm (Figure 2) without any complications. Her echocardiogram showed structurally normal heart. She was started on aspirin to reduce the risk of thrombosis and monitored for 24 hours without any complications. She was discharged with cardiology and obstetric follow-up.

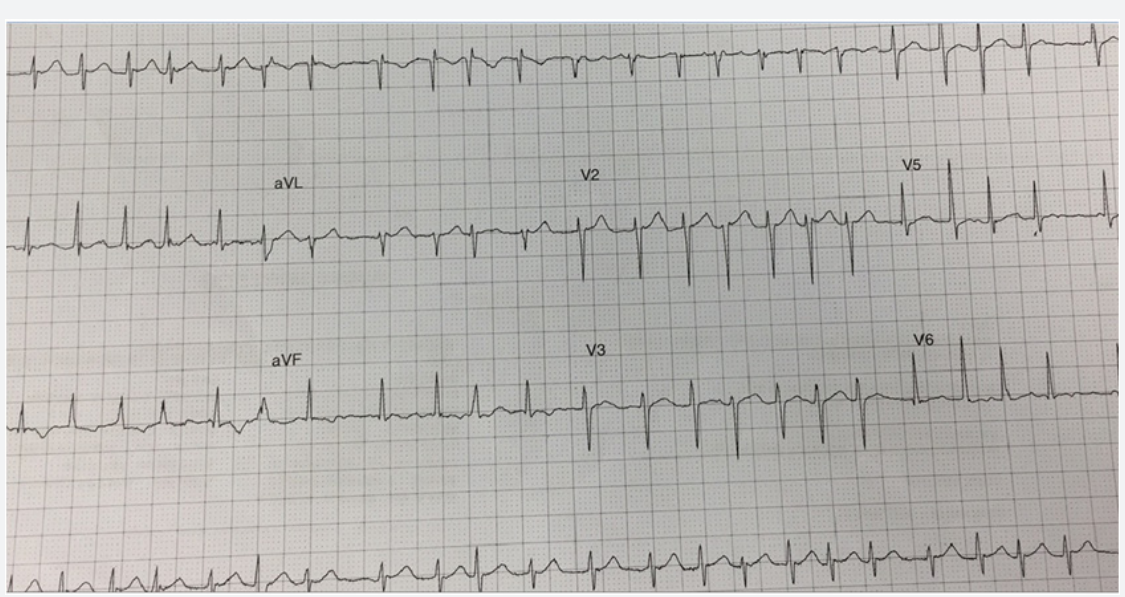

Figure 1: ECG showed atrial fibrillation with rapid ventricular response of 150 per minute. 


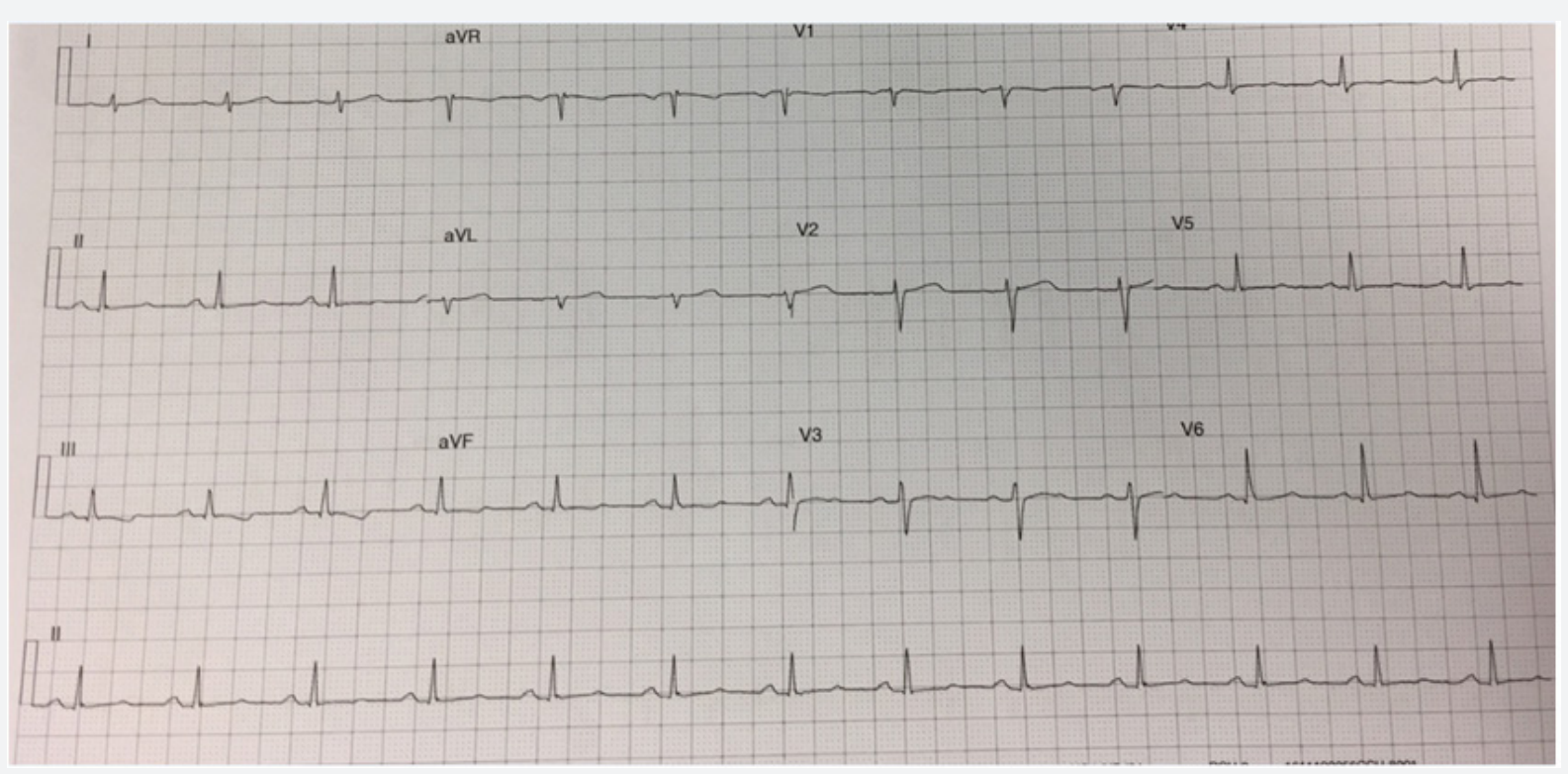

Figure 2: Normal sinus rhythm post cardio version

\section{Discussion}

New onset of lone atrial fibrillation in pregnancy is very rare in a structurally normal heart. A single centre study showed a prevalence of 2 in 100,000 pregnant women [2]. Women with underlying heart disease are more likely to present with haemodynamic compromise [3]. For example women with severe mitral stenosis tolerate atrial fibrillation poorly and may develop acute pulmonary edema due to high left atrial pressure [4]. One should exclude any cardiac abnormality with proper history, physical examination and appropriate cardiac investigations.

During pregnancy, a rhythm control strategy is often preferred over rate control strategy however there is no randomised control trial available to compare the efficacy of the two therapies in pregnant women. However the initial aim should be to control the heart rate and maintain the sinus rhythm to avoid any end organ damage including placenta.

Many antiarrhytmic drugs are teratogenic, therefore the adverse events should be kept in mind when treating pregnant women. According to European Society of Cardiology beta blockers are the 1st line treatment followed by calcium channel blockers. Digoxin can also be given but digoxin levels are unreliable due to interference with immunoreactive serum components [5]. For women who do not respond to pharmacological therapy and who are haemodynamically unstable or whenever the risk of ongoing atrial fibrillation is considered high for the mother or the fetus, the DC cardioversion (DCCV) up to 400 Joules can be safely performed which is a class IC recommendation [6]. In English literature, from 196544 case reports have been described where DCCV was applied during pregnancy with success rate of $93.2 \%$ (41 cases). DCCV success rate is found in 42 to $92 \%$ of non pregnant cases $[7,8]$. In rest of 3 cases, a normal sinus rhythm was achieved only after additional drug therapy. Two maternal deaths have been reported after DCCV [9]. Three cases of premature delivery have been reported [10].

Pharmacological cardioversion can be achieved with class $1 \mathrm{~A}$ agents (e.g procainamide, quinidine) [11] however they require monitoring due to proarrhythmic properties. Due to potential toxicity, amiodarone should only be used if other drugs fail to control the rhythm. Flecainide can be used in a structurally normal heart with atrioventricular nodal blocking agent [5]. Women with no cardiac abnormality and low CHADS2 score (less than 2) do not require anticoagulation and only aspirin may be appropriate. Those with higher thrombotic risk should be given low molecular weight heparin. Directly acting oral anticoagulants are currently not recommended in pregnancy due to toxicity profiles [5].

\section{Conclusion}

Atrial fibrillation is an uncommon pregnancy complication. Treatment decisions are difficult due to potential risk of medication toxicities. It is therefore essential for physicians to be aware of the management of arrhythmias in pregnancy. As data is limited, further clinical trials are warranted to explore the pathophysiology, morbidity, mortality and management of atrial fibrillation in pregnancy.

\section{Author Contributions}

Muhammad Imran Butt -Substantial contributions to conception and study design, Analysis and interpretation of data, revising it critically for important intellectual content, final approval of the version to be published.

Mudassar Latif -Acquisition of data, drafting the article, Final approval of the version to be published. 


\section{References}

1. Gilson GJ, Samaan S, Crawford MH, Qualls CR, Curet LB (1997) Changes in hemodynamics, ventricular remodeling, and ventricular contractility during normal pregnancy: a longitudinal study. Obstet Gynecol 89(6): 957-962.

2. Li JM, Nguyen C, Joglar JA, Hamdan MH, Page RL (2008) Frequency and outcome of arrhythmias complicating admission during pregnancy: experience from a high-volume and ethnically-diverse obstetric service. Clin Cardiol 31(11): 538-541.

3. Bryg RJ, Gordon PR, Kudesia VS, Bhatia RK (1989) Effect of pregnancy on pressure gradient in mitral stenosis. Am J Cardiol 63(5): 384-386.

4. Szekely P, Snaith L (1961) Atrial fibrillation and pregnancy. Br Med J 1(5237): 1407-1410.

5. Regitz-Zagrosek V, Blomstrom Lundqvist C, Borghi C, Cifkova R, Ferreira $\mathrm{R}$, et al. (2011) ESC Guidelines on the management of cardiovascular diseases during pregnancy. Eur Heart J 32(24): 3147-3197.

6. Oishi ML, Xing S (2013) Atrial fibrillation: management strategies in the emergency department. Emerg Med Pract 15(2): 1-26.

7. Boodhoo L, Mitchell AR, Bordoli G, Lloyd G, Patel N, et al. (2007) DC cardioversion of persistent atrial fibrillation: a comparison of two protocols. Int J Cardiol 114(1): 16-21.

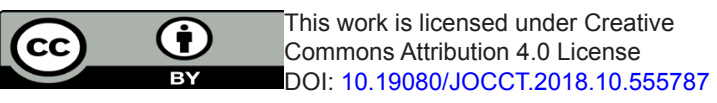

8. Paziaud O, Piot O, Rousseau J, Copie X, Lavergne T, et al. (2003) Predictive criteria of early recurrence of atrial arrhythmia after reduction by electrical cardioversion. Arch Mal Coeur Vaiss 96(12): 1169-1174.

9. Finlay AY, Edmunds V (1979) D.C. cardioversion in pregnancy. Br J Clin Pract 33(3): 88-94.

10. Barnes EJ, Eben F, Patterson D (2002) Direct current cardioversion during pregnancy should be performed with facilities available for fetal monitoring and emergency caesarean section. BJOG 109(12): 1406-1407.

11. Fuster V, Rydén LE, Cannom DS, Crijns HJ, Curtis AB, et al. (2006) ACC/ AHA/ESC 2006 guidelines for the management of patients with atrial fibrillation--executive summary: a report of the American College of Cardiology/American Heart Association Task Force on practice guidelines and the European Society of Cardiology Committee for Practice guidelines (writing committee to revise the 2001 guidelines for the management of patients with atrial fibrillation). J Am Coll Cardiol 48(4): 854-906.

\section{Your next submission with Juniper Publishers will reach you the below assets}

- Quality Editorial service

- Swift Peer Review

- Reprints availability

- E-prints Service

- Manuscript Podcast for convenient understanding

- Global attainment for your research

- Manuscript accessibility in different formats

( Pdf, E-pub, Full Text, Audio)

- Unceasing customer service

Track the below URL for one-step submission https://juniperpublishers.com/online-submission.php 